Jpn. J. Med. Mycol.

Vol. 48, 37-46, 2007

ISSN $0916-4804$

\title{
Original Article \\ Molecular Phylogenetics of Multiple Genes on Aspergillus Section Fumigati Isolated from Clinical Specimens in Japan
}

\author{
Takashi Yaguchi ${ }^{1 *}$, Yoshikazu Horie ${ }^{2}$, Reiko Tanaka ${ }^{1}$, \\ Tetsuhiro Matsuzawa ${ }^{1}$, Junko Ito ${ }^{1}$, Kazuko Nishimura ${ }^{1}$ \\ ${ }^{1}$ Research Center for Pathogenic Fungi and Microbial Toxicoses, Chiba University, \\ 1-8-1 Inohana, Chuo-ku, Chiba 260-8673, Japan \\ ${ }^{2}$ Natural History Museum and Institute Chiba, \\ 123 Yoshio, Katsura, Chiba 299-5242, Japan
}

〔Received: 1, August 2006. Accepted: 13, October 2006〕

\begin{abstract}
A phylogenetic study based on sequence analysis of the $\beta$-tubulin, hydrophobin and calmodulin genes was performed in 19 strains of Aspergillus fumigatus and related species isolated from clinical specimens in Japan. Correlations between detailed morphology and phylogeny were examined. Species in the section Fumigati were divided into five clades: clade I, typical strains of A. fumigatus; clade II, species including A. lentulus and A. fumisynnematus; clade III, species including A. fumigatiaffinis and A. novofumigatus, clade IV, atypical strains of A. fumigatus including A. viridinutans; and clade $\mathrm{V}$, species including A. brevipes, A. duricaulis and A. unilateralis. Most of the examined strains from clinical specimens in Japan clustered together in clade I and exhibit globose conidia with lobatereticulate ornamentation. Other strains from clinical specimens were divided into two clades (clades II and IV). The strains in clades II and the six strains in clade IV exhibit conidia with microtuberculate ornamentation, while A. viridinutans-complex in clades IV and the strains in clade $\mathrm{V}$ have conidia with lobate-reticulate ornamentation. The six strains are clearly distinguished from A. viridinutans-complex and are considered to be related to Neosartorya udagawae. The maximal growth temperatures of clades I, II, IV and V were above $50^{\circ} \mathrm{C}, 45^{\circ} \mathrm{C}, 42^{\circ} \mathrm{C}$ and $42^{\circ} \mathrm{C}$, respectively. These data are useful for classification of species within the Aspergillus section Fumigati.
\end{abstract}

Key words: Aspergillus Section Fumigati, clinical isolates in Japan, molecular phylogenetics

\section{Introduction}

Aspergillosis is a clinically important mycosis that comprises a wide variety of bronchopulmonary infections, such as invasive pulmonary aspergillosis, fungus ball in the lung cavity and allergic bronchopulmonary aspergillosis. The disease also manifests as corneal ulcer, nasal sinusitis with/without fungus balls and infections in the other organs and tissues. Among opportunistic fungal infections, invasive pulmonary aspergillosis is the most serious due to its high frequency and mortality rates. The causative agents are Aspergillus fumigatus, A. flavus, A. niger and other

Corresponding author: Takashi Yaguchi

Research Center for Pathogenic Fungi and Microbial

Toxicoses, Chiba University,

1-8-1 Inohana, Chuo-ku, Chiba 260-8673, Japan. species in this genus. The most significant causative agent is A. fumigatus and it has been reported that cases of invasive infections are caused by species of a related teleomorphic genus, Neosartorya ${ }^{1-3)}$.

However, clinical isolates of the species are not necessarily morphologically uniform, and mistaken identifications of them by morphological characteristics have often happened. In order to develop diagnostic techniques, including DNA identification and assessment of sensitivity to antifungal agents, it is essential to clarify intraand interspecies diversity in A. fumigatus and closely related species.

Several biochemical and molecular techniques have recently been applied to A. fumigatus and related species. Profiles of secondary metabolites produced by $A$. fumigatus and described varieties 
Table 1. List of taxa sequenced in this study and additional taxa included in the analysis

\begin{tabular}{|c|c|c|c|}
\hline Group & Taxon & Strain number & Origin (substrate) \\
\hline \multirow[t]{18}{*}{ I } & A. fumigatus & IAM $13869^{\mathrm{NT}}$ & USA（chicken） \\
\hline & A. fumigatus & IFM 47447 & Japan (human) \\
\hline & A. fumigatus & IFM 51745 & Japan (human) \\
\hline & A. fumigatus & IFM 51925 & Japan (horse) \\
\hline & A. fumigatus & IFM 51941 & Japan (human) \\
\hline & A. fumigatus & IFM 51942 & Japan (human) \\
\hline & A. fumigatus & IFM 51977 & Japan (human) \\
\hline & A. fumigatus & IFM 51978 & Japan (human) \\
\hline & A. fumigatus & IFM 53869 & Japan (human) \\
\hline & A. fumigatus & IFM 53870 & Japan (human) \\
\hline & A. fumigatus & IFM 53872 & Japan (human) \\
\hline & A. fumigatus & IFM 54304 & Japan (human) \\
\hline & A. fumigatus & CBS 112389 & Germany (indoor) \\
\hline & A. fumigatus & CBS 110.46 & Unknown \\
\hline & A. fumigatus & CBS 148.89 & France（corn oil） \\
\hline & A. fumigatus & CBS 386.75 & India（soil） \\
\hline & A. fumigatus var. ellipticus & CBS $487.65^{\mathrm{T}}$ & USA（human） \\
\hline & A. arvii & CBM FD-0144 & Finland (cow) \\
\hline \multirow[t]{14}{*}{ II } & A. lentulus & $\mathrm{FH} 5^{\mathrm{T}}$ & USA（human） \\
\hline & A. lentulus & FH7 & USA（human） \\
\hline & A. lentulus & IFM 41090 & Venezuela（soil） \\
\hline & A. lentulus & IFM 47063 & Japan (human) \\
\hline & A. lentulus & IFM 47457 & Japan (human) \\
\hline & A. lentulus & CBS 153.89 & USA（soil） \\
\hline & A. lentulus & CBS 175.97 & Netherlands（dolphin） \\
\hline & A. lentulus & CBS 116883 & Korea（soil） \\
\hline & A. lentulus & KACC 41642 & Korea（soil） \\
\hline & A. lentulus & MK245 & Australia (human) \\
\hline & A. fumisynnematus & IFM $42277^{\mathrm{T}}$ & Venezuela (soil) \\
\hline & A. fumisynnematus & $90-\mathrm{BP}-70$ & Brazil (soil) \\
\hline & A. fumisynnematus & 90-BP-177 & Brazil（soil） \\
\hline & Aspergillus sp. & JV3 & Unknown (cocoa beans) \\
\hline \multirow[t]{2}{*}{ III } & A. fumigatiaffinis & CBS $117194^{\mathrm{T}}$ & USA（fungus） \\
\hline & A. novofumigatus & CBS $117520^{\mathrm{T}}$ & Ecuador (soil) \\
\hline \multirow[t]{17}{*}{ IV } & Aspergillus sp. & IFM 5058 & Japan (human) \\
\hline & Aspergillus sp. & IFM 51744 & Japan (human) \\
\hline & Aspergillus sp. & IFM 53867 & Japan (human) \\
\hline & Aspergillus sp. & IFM 53868 & Japan (human) \\
\hline & Aspergillus sp. & IFM 54302 & Japan (human) \\
\hline & Aspergillus sp. & CBM FD-0143 & Japan (food) \\
\hline & Aspergillus sp. & MK285 & Australia (human) \\
\hline & A. viridinutans & IMI 062875 & Australia (dung) \\
\hline & A. viridinutans & IMI 133982 & Russia (soil) \\
\hline & A. viridinutans & IMI 182127 & Sri Lanka（plant） \\
\hline & A. viridinutans & IMI 280490 & Zambia (soil) \\
\hline & A. viridinutans & NRRL 6106 & Unknown \\
\hline & A. viridinutans & CBS $127.56^{\mathrm{T}}$ & Australia (dung) \\
\hline & A. viridinutans & IFM 54303 & Japan (human) \\
\hline & A. viridinutans & FRR 1266 & Australia (soil) \\
\hline & Aspergillus sp. & MK246 & Australia (human) \\
\hline & Aspergillus sp. & MK284 & Australia (human) \\
\hline \multirow[t]{4}{*}{$\mathrm{V}$} & A. brevipes & NRRL $2439^{\mathrm{T}}$ & Australia (soil) \\
\hline & A. duricaulis & NRRL $4021^{\mathrm{T}}$ & Argentina (soil) \\
\hline & A. unilateralis & NRRL 577 & Unknown \\
\hline & A. unilateralis & CBS $126.56^{\mathrm{T}}$ & Australia (soil) \\
\hline \multirow[t]{12}{*}{ Others } & Aspergillus sp. & NWS3 & Australia (human) \\
\hline & N. aureola & NRRL $2244^{\mathrm{T}}$ & Ghana（soil） \\
\hline & N. fennelliae (type A) & NRRL $5534^{\mathrm{T}}$ & USA（rabbit） \\
\hline & N. fennelliae (type a) & NRRL $5535^{\mathrm{T}}$ & USA (rabbit) \\
\hline & N. fischeri & NRRL $181^{\mathrm{T}}$ & Unknown \\
\hline & N. glabra & NRRL $2163^{\mathrm{T}}$ & USA（rubber） \\
\hline & N. hiratsukae & NRRL 20819 & Unknown \\
\hline & N. hiratsukae & IFM $47035^{\mathrm{T}}$ & Japan（aloe juice） \\
\hline & N. pseudofischeri & NRRL $20748^{\mathrm{T}}$ & USA (human) \\
\hline & N. spinosa & NRRL $5034^{\mathrm{T}}$ & Nicaragua（soil） \\
\hline & N. udagawae (type A) & CBM FA- $0702^{\mathrm{T}}$ & Brazil (soil) \\
\hline & N. udagawae (type a) & CBM FA-0703 ${ }^{\mathrm{T}}$ & Brazil (soil) \\
\hline \multirow[t]{2}{*}{ Out group } & A. clavatus & H522 & \\
\hline & A. oryzae & RIB40 & \\
\hline
\end{tabular}

T: type strain, NT: neotype strain 
are homogeneous ${ }^{4)}$. Isozyme electrophoretic patterns have been examined in the $A$. fumigatus complex by several groups ${ }^{5-8)}$. The phylogenetic relationships among A. fumigatus and related species have also been analyzed by sequencing parts of the $\beta$-tubulin ${ }^{9,10)}$ and cytochrome $b$ genes ${ }^{11)}$.

In 2005, species of poorly sporulating $A$. fumigatus found among clinical isolates in Australia were determined to be atypical $A$. fumigatus based on DNA sequence analysis of $18 \mathrm{~S}$ rDNA, and the alkaline protease and $\beta$ tubulin genes. Based on morphology, however, it was concluded that all isolates could be classified as $A$. viridinutans ${ }^{12)}$.

Aspergillus lentulus isolated from clinical specimens in USA was described as a new species ${ }^{13)}$. It is not able to survive at $48^{\circ} \mathrm{C}$, and is potentially drug resistant ${ }^{14)}$. The clade comprising this species was distinct from the A. fumigatuscomplex, which includes the varieties of $A$. fumigatus.

Variability within A. fumigatus and related species in Korea was recently examined using morphology, growth temperature regimens, extrolite patterns and DNA analyses of the partial $\beta$ tubulin, calmodulin and actin genes, and two new species, A. fumigatiaffinis and A. novofumigatus, were proposed ${ }^{15)}$.

We re-evaluated the identification of the $A$. fumigatus strains preserved at the Research Center for Pathogenic Fungi and Microbial Toxicoses, Chiba University (IFM), as causative agents of mycosis in human and animals. Because we identified morphologically atypical species of A. fumigatus, we then determined the phylogenetic relationships among A. fumigatus and related species, including Neosartorya species, by analyzing the DNA sequences of the partial $\beta$-tubulin, hydrophobin and calmodulin genes. Furthermore, correlations among detailed morphology, maximal growth temperatures, minimal inhibitory concentrations (MICs) of antifungal agents and phylogeny were analyzed.

\section{Materials and Methods}

\section{Fungal isolates}

Isolates were preserved at IFM and the Natural History Museum and Institute, Chiba, Japan (CBM), or were purchased from the Centraalbureau voor Schimmelcultures (CBS). Isolates are listed in Table 1.

\section{Incubation and observation}

Cultures were grown in incubators at $25^{\circ} \mathrm{C}$ or $37^{\circ} \mathrm{C}$. Fungal structure of isolates grown for 14 days on Czapek (CzA) or malt extract (MEA) agar was examined under a light or scanning electron microscope (SEM: Hitachi S-800, Tokyo, Japan). Colony colors are as designated in the Methuen Handbook of Colour ${ }^{16)}$.

\section{Growth studies}

The maximal growth temperatures of isolates were determined by the method of Balajee et $a l .{ }^{13)} ; 10 \mu l$ of conidial suspension $\left(10^{5}\right.$ conidia/ $\mathrm{m} l$ of sterile distilled water) was placed in the center of a $\mathrm{CzA}$ plate, which was incubated at $37,42,45,48$ or $50^{\circ} \mathrm{C}$ for 3 days. The presence or absence of growth at the end of the incubation period was then recorded.

\section{Mating test}

On oatmeal agar (1.5\% oatmeal, $1.5 \%$ wheat germ and $2 \%$ agar), mating tests were conducted with mating types "A" and "a" of N. udagawae and isolates in clade IV (Table 1). Plates were incubated at $25^{\circ} \mathrm{C}$ for 90 days, after which the presence or absence of ascomata formation was recorded. Mating between the "A" and "a" types of N. udagawae produced ascomata.

\section{Sequencing}

The $\beta$-tubulin, hydrophobin and calmodulin genes were sequenced directly from PCR products using primer pair Bt2a (5'-AATAGGTGCCGCTTTCTGG-3') and Bt2b (5'-AGTTGTCGGGACGGAAGAG-3') 17), primer pair rodA1 (5'-GCTGGCAATGGTGTTGGCAA-3') and $\operatorname{rodA2}$ (5'-AGGGCAATGCAAGGAAGACC-3') ${ }^{9)}$, and primer pair cmd5 (5'-CCGAGTACAAGGAGGCGTTC-3') and cmd6 (5'-CCGATAGAGGTCATAACGTGG-3') 15), respectively. PCR products were sequenced using the BigDye Terminator Cycle Sequencing Ready Reaction Kit (Applied Biosystems, Foster City, Calif., USA) on an ABI PRISM 3130 Genetic Analyzer (Applied Biosystems), according to the manufacturer's instructions.

\section{Molecular phylogenetic analysis}

DNA sequences were edited using ATGC Ver. 4 sequence assembly software (Genetyx Co., Tokyo, Japan), and alignment of the sequences was performed using Clustal $\mathrm{X}$ software ${ }^{18)}$. Maximum parsimony (MP) analysis ${ }^{19)}$ was performed by heuristic search with random addition sequences, branch swapping by tree bisection-reconnection (TBR) and MAXTREES set at 20000, using PAUP* 4b10 20). Relative robustness of the individual branches was estimated by bootstrapping ${ }^{21)}$, with 1000 


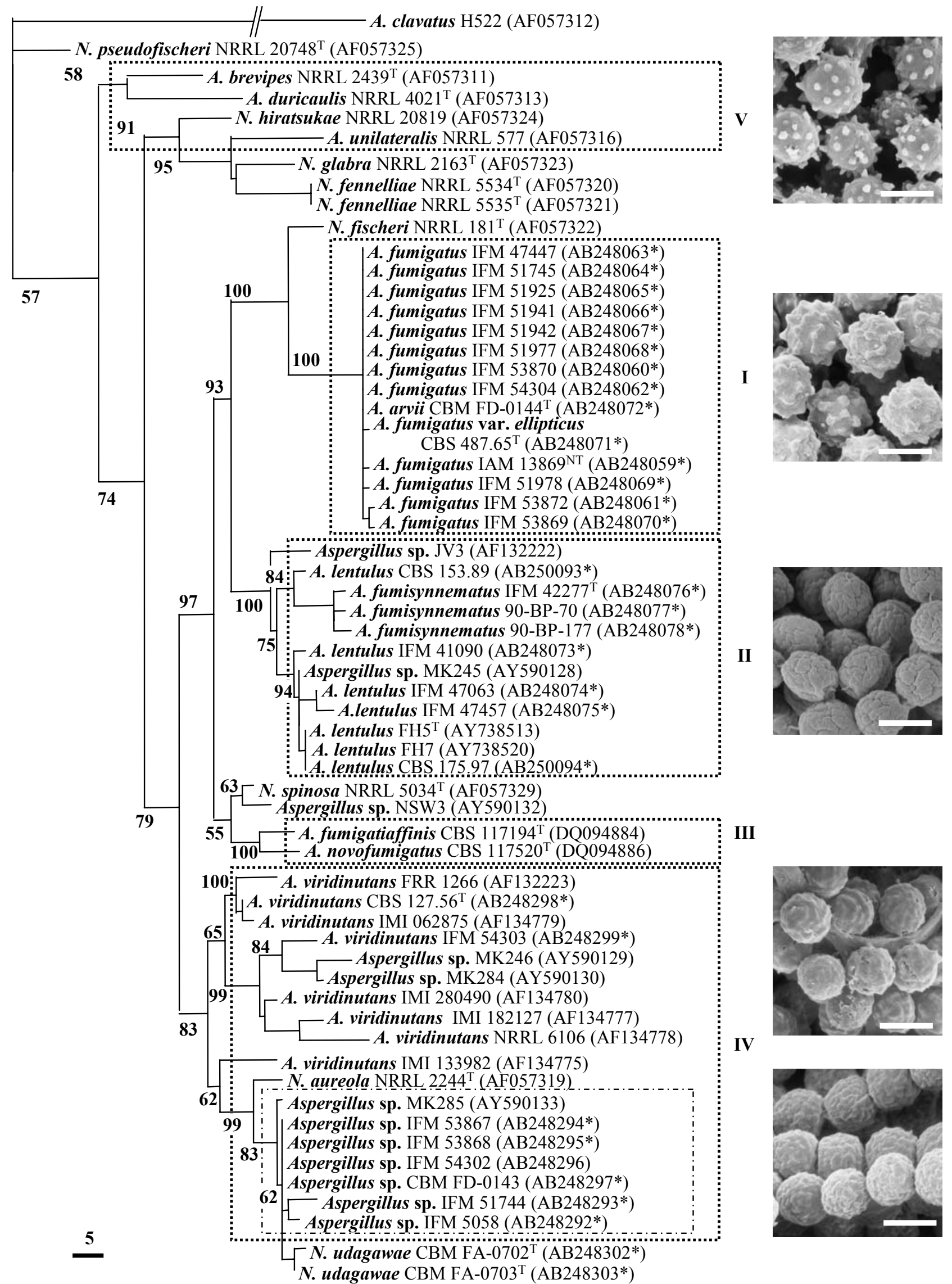

Fig. 1. One of 95 equally parsimonious trees obtained from analysis of the $\beta$-tubulin gene using PAUP. Trees were 459 steps in length with a CI of 0.721 and an RI of 0.879 . Numbers above or below the nodes represent bootstrap values of $>50 \%$ (out of 1000 bootstrap replications). A. Aspergillus; $N$. Neosartorya; *, this study. SEM photographs; conidia (scale bars $=3 \mu \mathrm{m}$ ). 


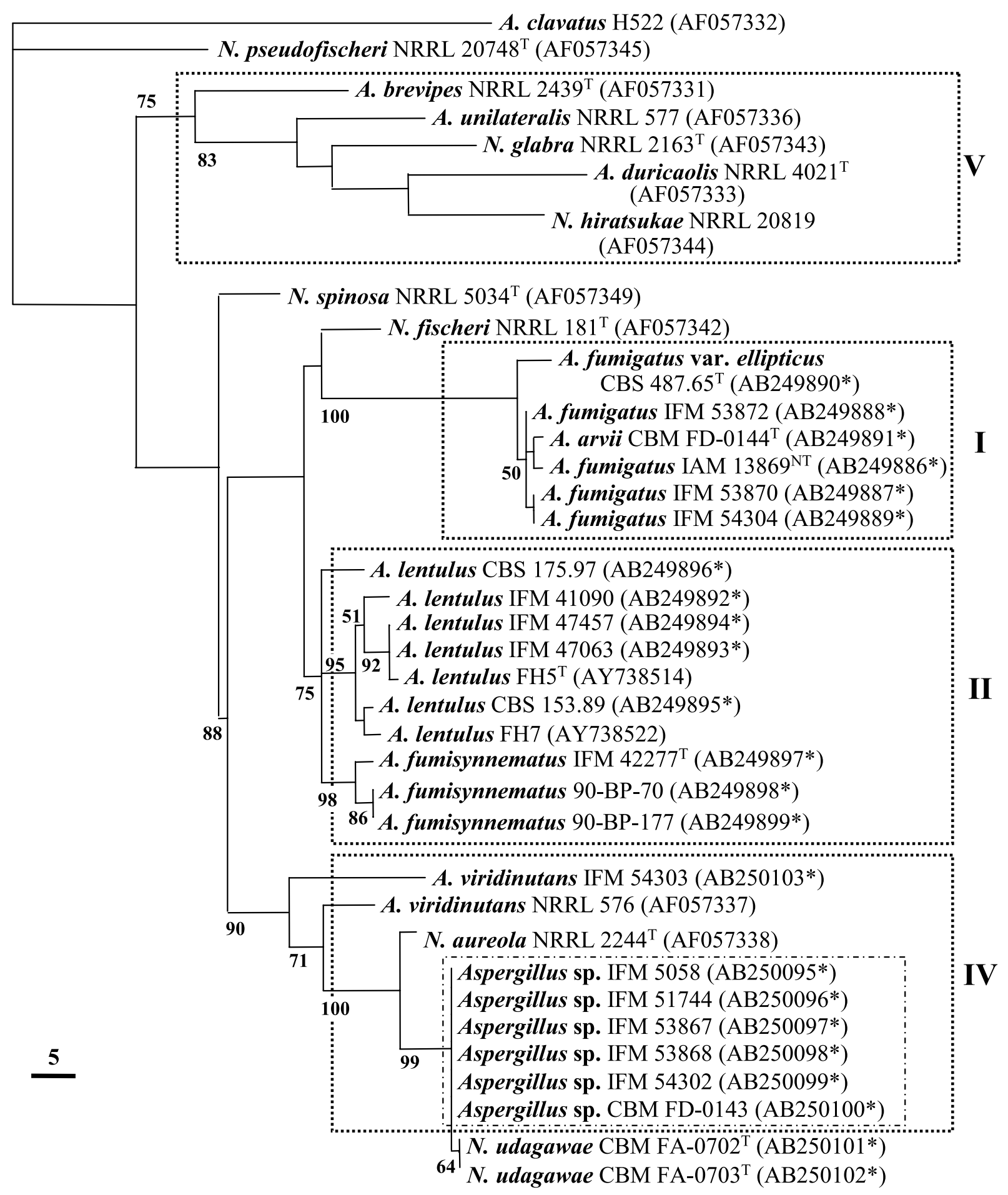

Fig. 2. One of six equally parsimonious trees obtained from analysis of the hydrophobin gene using PAUP. Trees were 368 steps in length with a CI of 0.690 and an RI of 0.819 . Numbers above or below the nodes represent bootstrap values of $>50 \%$ (out of 1000 bootstrap replications). A. Aspergillus; N. Neosartorya; *, this study.

replicates, using heuristic search and branch swapping by TBR and MAXTREES set at 100 . For neighbor-joining (NJ) analysis ${ }^{22)}$, the distances between sequences were calculated using Kimura's two-parameter model ${ }^{23)}$.

MICs of antifungal agents

MICs of antifungal agents against the isolated fungi were measured by the microdilution method, which was proposed for filamentous fungi by the National Committee for Clinical Laboratory Standards (NCCLS M38-A) ${ }^{24)}$. Microtiter plates (Dry Plate; Eiken Chemicals, Tokyo, Japan) containing lyophilized antifungals that were serially diluted two-fold were used according to the manufacturer's instructions, with slight 


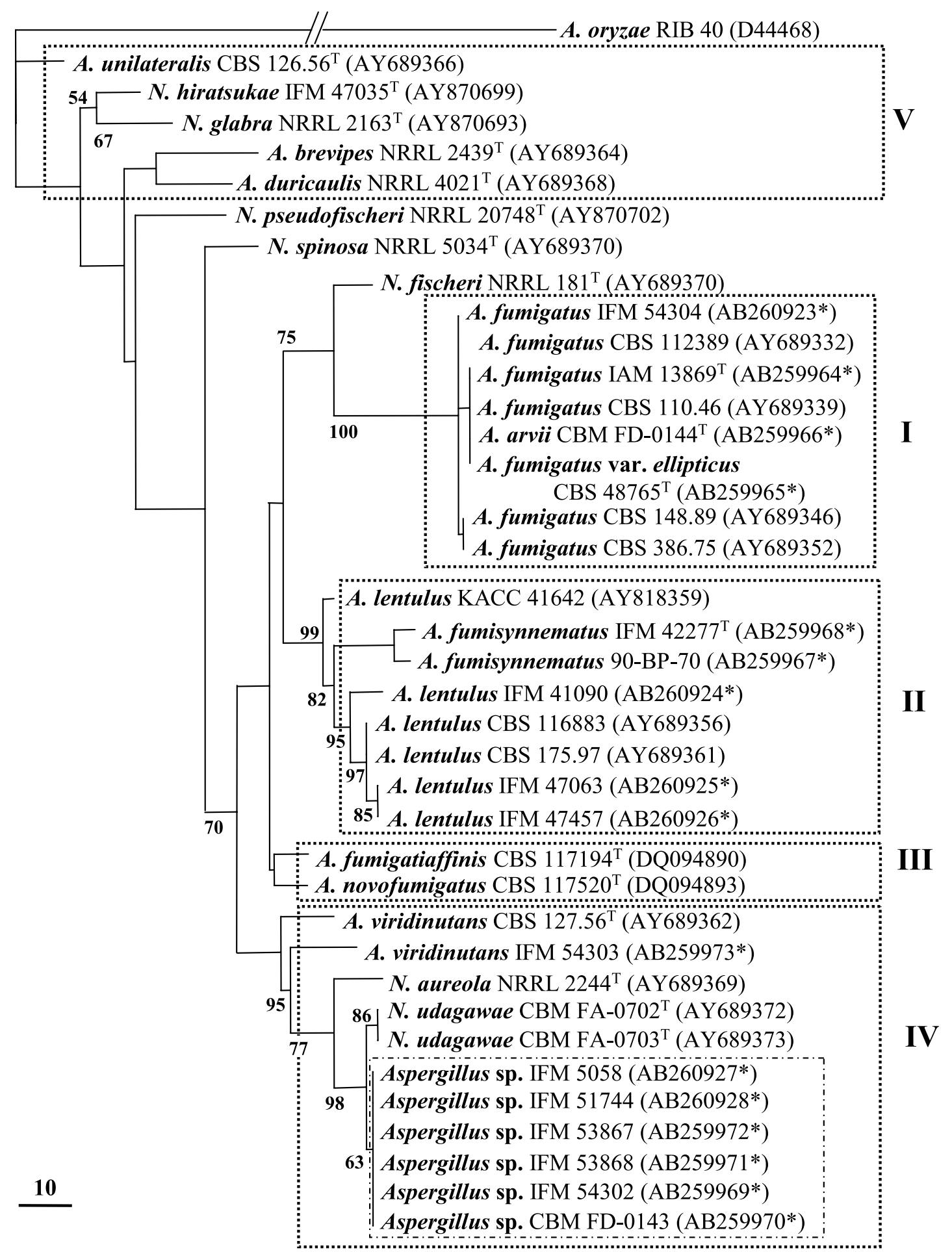

Fig. 3. One of 95 equally parsimonious trees obtained from analysis of the calmodulin gene using PAUP. Trees were 465 steps in length with a CI of 0.733 and an RI of 0.845 . Numbers above or below the nodes represent bootstrap values of $>50 \%$ (out of 1000 bootstrap replications). A. Aspergillus; N. Neosartorya; $*$ this study.

modification. The inoculum suspension was adjusted to $10^{4} \mathrm{CFU} / \mathrm{m} l$ in RPMI 1640 broth, added to the microtiter wells at $0.1 \mathrm{ml}$, and then incubated at $35^{\circ} \mathrm{C}$ for 48 hours. The growth control included the same inoculum in the absence of antifungals, while the negative control was sterile RPMI 1640 broth. Visual examination of growth inhibition was performed at 48 hours, as further incubation at 72 hours revealed the same reading.

\section{Results}

Phylogenetic analysis

DNA sequences of the partial $\beta$-tubulin, 
hydrophobin and calmodulin genes in the strains listed in Table 1 were determined. New sequences were deposited in the DNA Data Bank of Japan (DDBJ) and the accession numbers are listed in Figs. 1-3.

MP analysis of the $\beta$-tubulin gene sequences (Fig. 1) yielded 95 equally parsimonious trees based on 137 parsimony informative characters, 459 steps in length with a consistency index (CI) of 0.721 and a retention index (RI) of 0.879 . That of the hydrophobin gene sequences (Fig. 2) yielded six equally parsimonious trees based on 110 parsimony informative characters, 368 steps in length with a CI of 0.690 and an RI of 0.819 , and that of the calmodulin gene sequences (Fig. 3) yielded three parsimonious trees based on 145 parsimony informative characters, 465 steps in length with a CI of 0.733 and an RI of 0.845 . No differences were seen between tree topologies from MP and NJ analyses (NJ trees not shown) of the $\beta$-tubulin, hydrophobin and calmodulin genes.

The three trees based on the three loci were found to be similar. The species of the section Fumigati were divided into five clades: clade I, typical strains of A. fumigatus; clade II, species including $A$. lentulus and A. fumisynnematus; clade III, species including A. fumigatiaffinis and A. novofumigatus; IV, atypical strains of $A$. fumigatus including $A$. viridinutans; and clade V, species including $A$. brevipes, A. duricaulis and $A$. unilateralis. Most of the examined strains, including ex-neotype strain IAM 13869, clustered together in the same clade (clade I), while $A$. fumigatus var. ellipticus and A. arvii were also placed here. Other strains from clinical specimens in Japan were divided into two clades (clades II and IV). Clade II formed a sister group with clade I and included $A$. lentulus, A. fumisynnematus and three strains, IFM 47063, 47475 and 41090. Clade III was related to clades I and II and no strains from Japanese clinical specimens belonged to this clade. Clade IV was separated from clades I, II and III. The six variant isolates, IFM 5058, 51744, 53867, 53868, 54302 and CBM FD-0143, belonged to this clade and were closely related to two species of Neosartorya, N. udagawae and $N$. aureola. This clade also included all strains of $A$. viridinutans and strain IFM 54303 from a clinical specimen in Japan. A. brevipes, $A$. duricaulis and $A$. unilateralis clustered together in clade $\mathrm{V}$, which included no strains from clinical specimens.

\section{Morphology}

Conidium ornamentation on SEM in strains belonging to clade I was found to vary from almost smooth to echinulate; however, most strains were echinulate. This ornamentation was classified into the lobate-reticulate category ${ }^{25)}$. A. fumigatus var. ellipticus exhibited ellipsoidal conidia with almost smooth ornamentation, while that of $A$. arvii was lobatereticulate.

Strains IFM 47063, 47475 and 41090, which exhibited almost the same alignment as $A$. lentulus FH 5, were found to have subglobose conidia with microtuberculate ornamentation ${ }^{25)}$. Strains IFM 42277, 90-BP-70 and 177, which were in clade II and were identified as $A$. fumisynnematus, had ellipsoidal conidia with microtuberculate ornamentation and their colonies were floccose and grayish green.

The six strains in clade IV (IFM 5058, 51744,

Table 2. Maximum growth temperatures and MICs on species of Aspergillus section Fumigati

\begin{tabular}{|c|c|c|c|c|c|c|c|c|c|}
\hline \multirow{2}{*}{ Group } & \multirow{2}{*}{ Species } & \multirow{2}{*}{ Strain } & \multirow{2}{*}{$\begin{array}{l}\text { Maximum growth } \\
\text { temperature }\left({ }^{\circ} \mathrm{C}\right)\end{array}$} & \multicolumn{6}{|c|}{$\operatorname{MIC}(\mathrm{mg} / \mathrm{m} l) *$} \\
\hline & & & & AMPH & $5-\mathrm{FC}$ & $\mathrm{FCZ}$ & ITZ & $\mathrm{MCZ}$ & MCFG \\
\hline \multirow{5}{*}{ I } & A. fumigatus & IAM 13869 & $>50$ & 1 & $>64$ & $>64$ & 0.5 & 2 & $>16$ \\
\hline & A. fumigatus & CBS 110.46 & $>50$ & 0.5 & $>64$ & $>64$ & 0.5 & 4 & $>16$ \\
\hline & A. fumigatus & IFM 59125 & $>50$ & 1 & $>64$ & $>64$ & 0.5 & 4 & $>16$ \\
\hline & A. arvii & CBM FD-0144 & $>50$ & 1 & $>64$ & $>64$ & 0.5 & 2 & $>16$ \\
\hline & A. fumigatus var. ellipticus & CBS 478.65 & $>50$ & 1 & 32 & $>64$ & 0.5 & 2 & $>16$ \\
\hline \multirow{4}{*}{ II } & A. lentulus & IFM 47457 & 45 & 2 & $>64$ & $>64$ & 0.5 & 4 & $>16$ \\
\hline & A. lentulus & IFM 47063 & 45 & 2 & $>64$ & $>64$ & 1 & 32 & $>16$ \\
\hline & A. lentulus & CBS 175.97 & 45 & 2 & $>64$ & $>64$ & 1 & 4 & $>16$ \\
\hline & A. fumisynnematus & IFM 42277 & 45 & 1 & $>64$ & $>64$ & 1 & 2 & $>16$ \\
\hline \multirow{3}{*}{ IV } & Aspergillus sp. & IFM 51744 & 42 & 1 & 64 & $>64$ & 0.5 & 2 & $>16$ \\
\hline & Aspergillus sp. & IFM 53868 & 42 & 1 & 64 & $>64$ & 1 & 32 & $>16$ \\
\hline & Aspergillus sp. & IFM 54302 & 42 & 1 & $>64$ & $>64$ & 1 & 2 & $>16$ \\
\hline \multirow[t]{2}{*}{$\mathrm{V}$} & A. viridinutans & CBS127.56 & 42 & 1 & 64 & $>64$ & 0.5 & 1 & $>16$ \\
\hline & A. viridinutans & IFM 54303 & 42 & 1 & $>64$ & $>64$ & 2 & $>32$ & $>16$ \\
\hline
\end{tabular}

* MICs shown were determined by the NCCLS methods. AMPH=amphotericin B, 5-FC=flucytosine, FCZ $=$ fluconazole, ITZ= itraconazole, $\mathrm{MCZ}=$ miconazole, $\mathrm{MCFG}=$ micafungin. 
53867, 53868, 54302 and CBM FD-0143) had globose conidia with microtuberculate ornamentation, while the ex-type strain of $A$. viridinutans CBS 127.56 had finely echinulate conidia classified as lobate-reticulate. Therefore, these strains were distinguished from $A$. viridinutans by conidia ornamentation. Furthermore, most strains of $A$. viridinutans possessed nodding vesicles.

The strains in clade VI had globose conidia with lobate-reticulate ornamentation, which were identical to those of typical A. fumigatus.

\section{Maximal growth temperature}

Strains belonging to clade I, including $A$. fumigatus var. ellipticus and $A$. arvii, grew at more than at $50^{\circ} \mathrm{C}$. Strains belonging to clade II grew poorly at $45^{\circ} \mathrm{C}$ and did not grow at $48^{\circ} \mathrm{C}$, while those belonging to clades IV and $\mathrm{V}$ grew well at $42^{\circ} \mathrm{C}$ but did not grow at $45^{\circ} \mathrm{C}$ (Table 2).

\section{Mating test}

Mating between the six strains in clade IV (IFM 5058, 51744, 53867， 53868， 54302 and CBM FD-0143) and mating types "A" and "a" of $N$. udagawae did not occur.

\section{MIC of antifungal agents}

MICs of antifungal agents against the isolates are listed in Table 2. The MIC of amphotericin $\mathrm{B}(\mathrm{AMPH})$ in A. lentulus was high when compared with other species.

\section{Discussion}

Our results concurred with those of Katz et al. ${ }^{12)}$ and Hong et al. ${ }^{15)}$ regarding the outline of phylogenetic trees based on DNA sequences of the $\beta$-tubulin gene. Namely, typical strains of $A$. fumigatus clustered in clade I (2a by Katz et al., A. fumigatus s. str. by Hong et al.) and all strains of $A$. viridinutans clustered in clade IV (1a and $1 \mathrm{~b}$ by Katz et al., A. viridinutanscomplex by Hong et al.). Varga et al. ${ }^{26)}$ showed that all strains of $A$. viridinutans belonged to a cluster based on the $\beta$-tubulin gene. However, we found six unknown strains in clade IV. The sequences of the hydrophobin and calmodulin genes gave trees with identical topology as that based on the $\beta$-tubulin gene. These strains are very closely related to $N$. udagawae, a heterothallic species, isolated from soil in Brazil ${ }^{27)}$. However, mating between the strains and $N$. udagawae did not occur. It is often difficult to do successful mating experiments on clinical isolates and fungi that have been routinely sub-cultured. Therefore these strains need to be further investigated before they are identified as the anamorphic state of $N$. udagawae. The strains have conidia with microtuberculate ornamentation, while $A$. viridinutans has conidia with lobatereticulate ornamentation. The maximal growth temperature of this species is $42^{\circ} \mathrm{C}$, which differs from those of A. fumigatus and A. lentulus. This phenotype is important and helpful to rapidly classify the species in the section Fumigati.

Strain CBM FD-0143 belonging to clade IV was isolated from food in Japan and was found to produce the neurotropic mycotoxins fumitremorgin A and ${ }^{28)}$. Strain IFM $5058^{29)}$ was isolated from a corneal ulcer and showed invasiveness in a mouse brain infection model, and it was also found to belong to this clade. Aspergillus sp. MK 285 12) isolated from the respiratory tract of a cat in Australia was included in this clade based on $\beta$-tubulin gene sequence, and is considered to be closely related to those strains. Additional study is necessary to confirm the identity of the Australian isolate.

Strains IFM 47063 and 47457 from clinical specimens in Japan were identified as $A$. lentulus, which was proposed as a new species demonstrating low in vitro susceptibility to antifungal drugs, including amphotericin B and itaconazole $^{13,14)}$. Our MP tree based on the $\beta$ tubulin gene had the same topology of the ML tree by Balajee et al. ${ }^{13)}$ among $A$. fumigatus, $A$. lentulus and $N$. fischeri. These strains had smaller conidial heads than A. fumigatus, did not survive at $48^{\circ} \mathrm{C}$ and had the same susceptibilities as A. lentulus (Table 2). Therefore, they are considered to belong to $A$. lentulus based on phylogeny, and morphological and physiological characteristics. According to de Hoog et al. ${ }^{30)}$, the MICs of AMPH for A. fumigatus ranged from $0.125 \mu \mathrm{m} / \mathrm{m} l$ to $2 \mu \mathrm{m} / \mathrm{m} l$. It was confirmed that Japanese isolates of $A$. lentulus had lower susceptibility to AMPH than typical isolates of A. fumigatus. Strain IFM 41090 from soil in Venezuela was also identified as $A$. lentulus and this species was reported to be isolated from clinical specimens in USA and Australia, soils in Korea and a dolphin in the Netherlands ${ }^{13,}{ }^{15}$ ). Therefore, A. lentulus is widely distributed in the world and the number of mycoses caused by this species is expected to increase from now.

Aspergillus fumigatus var. ellipticus is known to be a human pathogen and is distinguished from A. fumigatus by light yellow/green, short conidial heads and ellipsoidal, smooth or nearly so conidia, while A. fumigatus has dark green, 
long conidial heads and globose echinulate conidia $^{31)}$. In 1989 , Kozakiewicz ${ }^{25)}$ promoted this variety to an identical species, A. neoellipticus, which resulted in much debate regarding species independence. Our results showed that for three different genes, the ex-type strain of A. fumigatus var. ellipticus (CBS 487.65) could not be distinguished from the strains identified as $A$. fumigatus, including the ex-neotype strain IAM 13869. Similar data were seen for $\beta$ tubulin and hydrophobin gene analysis 9,13$)$ and mitochondrial cytochrome $b$ gene analysis ${ }^{11)}$. However, there has been no discussion regarding molecular phylogenetic analysis and morphology examined under SEM. The ornamentation of conidia on A. fumigatus var. ellipticus is almost smooth, while that of A. fumigatus is lobatereticulate. Therefore, this taxon should remain as a variety of $A$. fumigatus, and A. fumigatus var. ellipticus is a suitable name.

In 1994, A. arvii was isolated from liver lesions in a dairy cow in Finland and was reported as a new species classified in section Fumigati based on its buff color on all standard media ${ }^{32)}$. This characteristic is not found in the original descriptions of A. fumigatus. However, this taxon has the same alignment with typical species of $A$. fumigatus in three different genes. Moreover, the shape and ornamentation of the conidia are the same as those of $A$. fumigatus. Therefore, it was concluded that this taxon is a variety of $A$. fumigatus.

Aspergillus fumigatiaffinis and A. novofumigatus were recently proposed as two new species ${ }^{15)}$ clustered together with $N$. spinosa on the $\beta$ tubulin gene. We have not found any strains related to the two species. These taxa were isolated from soils in Korea and Ecuador. Therefore, additional isolates identified as these species will be identified with further research.

Aspergillus brevipes, A. duricaulis and A. unilateralis were very distant from other members of the section Fumigati. All three species are known from their type strains or very few isolates ${ }^{25)}$, and so are not considered clinically important.

In conclusion, we found that species of Aspergillus section Fumigati were divided into five clades, and there were correlations regarding phylogeny, morphology and physiological characteristics. The present polyphasic analysis demonstrates its ability to classify pathogenic fungi and its great potential as a tool in developing diagnostic techniques and in clarifying pathogenesis and epidemiology.

\section{Acknowledgements}

This work was supported in part by the National Bioresource Project-Pathogenic microbes in Japan (http://www.nbrp.jp/) and a Grant-in-Aid for Scientific Research (C-18510201, 18927002) from the Japan Society for the Promotion of Science.

\section{References}

1) Balajee SA, Gribskov J, Brandt $M$, Ito J, Fothergill A, Marr KA: Mistaken identity: Neosartorya pseudofischeri and its anamorph masquerading as Aspergillus fumigatus. J Clin Microbiol 43: 5996-5999, 2005.

2) Guarro J, Kallas EG, Godoy P, Karenina A, Gene J, Stchigel A, Colombo AL: Cerebral aspergillosis caused by Neosartorya hiratsukae, Brazil Emerg Infec Dis 8: 989-991, 2002.

3) Järv H, Lehtmaa J, Summerbell RC, Hoekstra ES, Samson RA, Naaber P: Isolation of Neosartorya pseudofischeri from blood: First hint of pulmonary aspergillosis. J Clin Miclobiol 42: 925-928, 2004.

4) Frisvad JC, Samson RA: Chemotaxnomy and morphology of Aspergillus and related taxa, In Modern concepts in Penicillium and Aspergillus classification. R.A. Samson and J.I. Pitt (ed.), pp.201-208. Plenum Press, New York, 1990.

5) Lin DM, Lehmann PF, Hamory BH, Padhye AA, Durry E, Pinner RW, Lasker BA: Comparison of three typing methods for clinical and environmental isolates of Aspergillus fumigatus. J Clin Microbiol 33: 1596-1601, 1995.

6) Matsuda H, Kohno S, Maesaki S, Yamada H, Koga H, Tamura M, Kuraishi H, Sugiyama J: Application of ubiquinone systems and electrophoretic comparison of enzymes to identification of clinical isolates of Aspergillus fumigatus and several other species Aspergillus. J Clin Microbiol 30: 1999-2005, 1992.

7) Rinyu E, Varga J, Ferenczy L: Phenotypic and genotypic analysis of variability in Aspergillus fumigatus. J Clin Microbiol 33: 2567-2575, 1995.

8) Rodriguez E, de Meeus T, Mallié M, Symoens F, Mondon P, Piens MA, Lebeau B, Viviani MA, Geillot R, Nolard N, Chapuis F, Tortorano AM, Bastide JM: Multicentric epidemiology study of Aspergillus fumigatus isolated by multilocus emzyme electrophoresis. J Clin Microbiol 34: 2559-2568, 1996.

9) Geiser DM, Frisvad JC, Taylor JW: Evolutionary relationships in Aspergillus section Fumigati inferred from partial $\beta$-tubulin and hydrophobin DNA sequences. Mycologia 90: 831-845, 1998.

10) Varga J, Vide Z, Toth B, Debets F, Horie Y: Phylogenetic analysis of newly described Neosartorya species. Antonie Leeuwenhoek 77: 235-239, 2000. 
11) Wang L, Yohoyama K, Miyaji M, Nishimura K: Mitochondrial cytochrome $b$ gene analysis of Aspergillus fumigatus and related species. J Clin Miclobiol 38: 1352-1358, 2000.

12) Katz ME, Dougall AM, Weeks K, Cheetham BF: Multiple genetically distinct group revealed among clinical isolates identified as atypical Aspergillus fumigatus. J Clin Miclobiol 43: 551$555,2005$.

13) Balajee SA, Gribskov JL, Hanley E, Nickle D, Marr K: Aspergillus lentulus sp. nov., a new sibling species of A. fumigatus. Eukaryotic Cell 4: 625-632, 2005.

14) Balajee SA, Weaver $M$, Imhof $A$, Gribskov $J$, Marr KA: Aspergillus fumigatus variant with decreased susceptibility to multiple antifungals. Antimicrob Agents Chmother 48: 1197-1203, 2004.

15) Hong S-B, Go S-J, Frisvad JC, Samson R: Polyphasic taxonomy of Aspergillus fumigatus and related species. Mycologia 97: 1316-1329, 2005.

16) Kornerup A, Wanscher JH: Methuen Handbook of Colour, 3rd ed. Eyre Methuen, London, 1978.

17) Glass NL, Donaldson GC: Development of primer sets designed for use with the PCR to amplify genes from filamentous ascomycetes. Appl Environ Microbiol 61: 1323-1330, 1995.

18) Thompson JD, Gibson TJ, Plewniak F, Jeanmougin F, Higgins DG: The clustal $\mathrm{X}$ windows interface: flexible strategies for multiple sequence alignment aided by quality analysis tools. Nucleic Acids Res 24: 4876-4882, 1997.

19) Fitch WM: On the problem of discovering the most parsimonious tree. Am Nat 111: 223-257, 1977.

20) Swofford DL: PAUP*: phylogenetic analysis using parsimony (*and other methods). Version $4 \mathrm{~b} 10$. Sunderland, Massachusetts: Sinauer Associate, 2002.

21) Felsenstein J: Confidence limits on phylogenies:
An approach using the bootstrap. Evolution 39: 783-791, 1985.

22) Saitou N, Nei M: The neighbor-joining method: A new method for reconstructing phylogenetic trees. Mol Biol Evol 4: 406-425, 1987.

23) Kimura M: A simple method for estimating evolutionary rate of base substitutions through comparative studies of nucleotide sequences. J Mol Evol 16: 111-120, 1980.

24) National Committee for Clinical Laboratory Standards. Reference method for broth dilution antifungal susceptibility testing of filamentous fungi. Approved standard M38-A. National Committee for Clinical Laboratory Standards. Wayne, Pa, 2002.

25) Kozakiewicz Z: Aspergillus species on the stored products. Mycol Pap 161: 1-181, 1989.

26) Varga J, Toth B, Rigo K, Debets F, Kozakiewicz Z: Genetic variety within the Aspergillus viridinutans species. Folia Microbiol 45: 423-428, 2000.

27) Horie $\mathrm{Y}$, Miyaji M, Nishimura $\mathrm{K}$, Franco MF, Coelho KIR: New and interesting species of Neosartorya from Brazilian soil. Mycoscience 36: 199-204, 1995.

28) Yamazaki M, Suzuki S, Miyaki K: Tremorgenic toxins from Aspergillus fumigatus Fres. Chem Pharm Bull 19: 1739-1740, 1971.

29) Nishimura K, Miyaji M: Studies on the growth of Aspergillus fumigatus in the brain of mouse. Jpn J Med Mycol 12: 24-29, 1971.

30) De Hoog G.S, Guarro J, Gené J, Figueras MJ: Aspergillus fumigatus. In Atlas of Clinical Fungi, 2nd ed. pp.473-475, Centraalbureau voor Schimmelcultures, Utrecht, 2000.

31) Raper KB, Fennell DI: The Aspergillus fumigatus group. In The genus of Aspergillus (Raper KB, Fennell DI ed), pp.238-268, The Williams \& Wilkins Co., Baltitimore, 1965.

32) Aho R, Horie $\mathrm{Y}$, Nishimura K, Miyaji M: Aspergillus arvii spec. nov., a new animal pathogen? Mycoses 37: 389-392, 1994. 